\title{
Sistema de inovação e crescimento econômico: uma análise de painel dinâmico para o período 2006-2016
}

\section{Innovation and economic growth system: an analysis of dynamic panel for the period 2006-2016}

\author{
Raniella Orquiza da Silva* \\ Waldemiro Peterle Neto* \\ Evandro Camargos Teixeira*
}

\begin{abstract}
There is no consensus on the definition and measurement of economic development, since it is a topic that encompasses issues related to economic, social, cultural and political changes. Considering growth and economic development as similar concepts, this study, through factor analysis, extracted six factors. Based on the factors, six rankings indicating the performance of capacities were developed, with Singapore as a hegemonic nation among its peers. Still, based on the dynamic panel data model, it was found that, for the period from 2006 to 2016, the innovation system was the main factor for the economic progress of developing countries.
\end{abstract}

Keywords: innovation, developing countries, econometrics.

\section{Resumo}

Não há consenso sobre a definição e mensuração do desenvolvimento econômico, já que é um tema que engloba questôes relacionadas às mudanças econômicas, sociais, culturais e políticas. Considerando crescimento e desenvolvimento econômico como conceitos similares, o presente estudo, através da análise fatorial, extraiu seis fatores que forneceram seis rankings indicadores de desempenho das capacidades, sendo evidenciado Singapura como nação hegemônica entre seus pares. Ainda, constatou-se, a partir do modelo de dados em painel dinâmico, que, para o período de 2006 a 2016, o sistema de inovação foi o principal fator para o progresso econômico dos países em desenvolvimento.

Palavras-chave: inovação, países em desenvolvimento, econometria.

* Universidade Federal de Viçosa, correos-e: raniellasilva21@gmail.com, walde.neto@hotmail. com y evandro.teixeira@ufv.br 


\section{Introdução}

Ao valer-se das concepçóes tanto da teoria econômica tradicional quanto da teoria política, o desenvolvimento econômico busca incorporar em suas análises, além da preocupação com a alocação ótima dos recursos, questôes relacionadas às mudanças sociais, culturais e políticas, de forma que as transformações estruturais e institucionais decorrentes dessas mudanças incorram em progresso econômico para os diversos segmentos populacionais.

Pela abrangência do conceito, estudos empíricos apresentam variaçóes quanto a definição e mensuração do desenvolvimento econômico. Por simplicidade, no entanto, considera-se desenvolvimento como sinônimo de crescimento econômico, de forma que sejam captados os diferentes níveis de progresso sustentado dos países através da variação do Produto Interno Bruto (PIB) per capita.

Os determinantes do crescimento econômico, contudo, não são passíveis de tamanha simplificação. A economia clássica ${ }^{1}$ considerava que o crescimento econômico se resumia à quantidade de capital acumulado por trabalhador. Já a teoria do crescimento endógeno, a partir de indagaçôes a respeito do modelo clássico, reconhece a tecnologia (conhecimento) como principal determinante para o crescimento sustentado (Romer, 2001).

No entanto, tal conhecimento apresenta caráter não rival e excludente, de modo que mesmo estando disponível para todos, só é adquirido por países que desenvolverem algumas capacidades (Romer, 2001). Nesse sentido, surge na literatura conceitos como o de Capacidade de Absorção, que ressalta o valor que se atribui às informaçôes externas, conferindo grande importância ao grau de abertura do país e sua interação com seus pares (Cohen and Levinthal, 1990).

Com certa similaridade, o termo de Capacidade Tecnológica, definido por Choi (2007), é atrelado ao esforço da nação em utilizar, adaptar e modificar as tecnologias existentes, sendo considerado, então, a competência do país em inovar e realizar investimentos produtivos. Essa capacidade tecnológica está, portanto, associada ao que Edquist (2009) denominou de Sistema Nacional de Inovação, conceito utilizado no presente estudo e determinante fundamental do crescimento econômico, conforme a literatura.

Paralelamente, surge outro conceito importante: o de Capacidade Social, que contempla as habilidades (individuais e coletivas), bem como a interação do setor público com privado (Abramovitz, 1986). Consequentemente, a qualidade da educação, a boa gestão das empresas e a

\footnotetext{
${ }^{1}$ Para maior compreensão, ver Romer (2001).
} 
honestidade dos governantes tendem a ser essenciais para o crescimento dos países.

$\mathrm{Na}$ literatura, ao se reconhecer o papel central da tecnologia como motor do crescimento, diversos trabalhos, em suas análises econométricas, buscaram incluir as capacidades como determinantes do crescimento econômico, sendo que a capacidade tecnológica demonstrou especial relevância para explicar os diferentes níveis de progresso econômico entre os países (Fagerberg and Srholec, 2005; 2008; 2017; Fagerberg et al., 2007; 2017).

No entanto, esses trabalhos incluíram em suas observaçóes países desenvolvidos e em desenvolvimento, o que pode ser questionável. Nelson (1993) destaca que os países com baixo nível de renda apresentam vantagem comparativa e padróes de demanda interna diferentes dos países desenvolvidos, e essas diferenças moldam profundamente a complexidade econômica desses grupos. Mais precisamente, os países em desenvolvimento possuem economias vinculadas ao mercado de commodities e recursos naturais, que são altamente imperfeitos, tendo em vista que os consumidores e os produtores não possuem informaçôes ilimitadas. Ademais, mudanças estruturais e institucionais importantes não estáo consolidadas, ocorrendo equilíbrios múltiplos ao invés de um único equilíbrio, sendo que as situações de desequilíbrio geralmente prevalecem (Todaro and Smith, 2012).

Dessa forma, o presente estudo, partindo da hipótese de que o sistema de inovação é o principal fator para o progresso econômico, busca contribuir com a literatura ao estabelecer como objetivo a análise dos determinantes do crescimento econômico, especificamente para os países em desenvolvimento, em um cenário mais recente. Ademais, ao contrário dos estudos citados, utiliza-se aqui a metodologia de dados em painel dinâmico, uma vez que considera-se a existência de endogeneidade entre o desenvolvimento e as capacidades.

Além da presente introdução, o trabalho se divide em outras quatro seçóes. A segunda seção realiza uma revisão da literatura, apontando como os trabalhos captaram as capacidades dos países, bem como estas foram determinantes para o crescimento econômico. Na terceira seção, é apresentada a análise fatorial, necessária para agrupar variáveis correlacionadas e, complementarmente, a metodologia de dados em painel dinâmico. $\mathrm{Na}$ quarta parte é realizada discussáo a respeito dos resultados e, por fim, a última seção ressalta as consideraçóes finais. 


\section{Aspectos teóricos e empíricos}

Estudos que abordam a temática do crescimento econômico frequentemente buscam agrupar um número expressivo de variáveis que estáo correlacionadas, de forma a captar, a partir de modelos econométricos, o efeito da complexidade dos conceitos de capacidade tecnológica, capacidade de absorção e capacidade social sobre o crescimento dos países.

Como já exposto, essas capacidades apresentam diversas dimensóes, o que resulta em diferentes denominaçóes na literatura. Fagerberg e Srholec (2005), objetivando incluir em seus estudos uma variável que englobasse o conceito de capacidade tecnológica, uniram em um único fator, nomeado de "Conhecimento", variáveis como despesas em pesquisas e desenvolvimento; número de patentes; artigos publicados em revistas científicas e técnicas; infraestrutura de Tecnologia da Informação e Comunicação (TIC); bem como a certificação ISO 9000. Já Fagerberg e Srholec (2008), ao acrescentar às referidas variáveis o aspecto educacional dos países, designa ao fator o nome de "Sistema de Inovação". Outros trabalhos, como os realizados por Fagerberg et al. (2007; 2017) denotam ao fator que apresenta variáveis similares, o título de "Competitividade Tecnológica" e "Capacidades", respectivamente.

Dessa forma, todas essas denominaçóes podem ser intercambiáveis quando busca-se incluir o conceito de capacidade tecnológica na pesquisa. Contudo, mais importante do que ressaltar as diversas formas que tal capacidade se apresenta na literatura, é evidenciar que todos os estudos citados apresentam a capacidade tecnológica como um fator que está significativamente e positivamente relacionado ao crescimento. Assim, mesmo em diferentes períodos de análise, o fator construído a partir de variáveis que estão fortemente ligadas à pesquisa e desenvolvimento tende a ser crucial para explicar os diferentes níveis de crescimento entre países.

A complexidade e relevância da capacidade tecnológica é apresentada como Sistema Nacional de Inovação (SNI) por Nelson (1993). O autor demonstra que a própria definição de inovação não é simples, ainda mais se tratando de países em desenvolvimento, uma vez que aprender e adaptar uma tecnologia criada por economias industrializadas, ou seja, realizar engenharia reversa, é um processo inovativo. Ademais, o conceito de Sistema traz a ideia de dinâmica entre governo, empresas e universidades para influenciar o desempenho inovador. Basicamente, a forma como esses atores institucionais conduzem o sistema de ensino, treinamento, ambientes regulatório, macro e microeconômico moldam o sistema inovativo (Freeman, 1995).

Em contrapartida, o conceito de capacidade de absorção, muito associado ao comércio internacional, apresenta-se na literatura de forma mais 
homogênea. Fagerberg e Srholec (2005; 2008), bem como Fagerberg et al. (2017) inserem em seus modelos de análise dos determinantes do crescimento um fator intitulado como "Abertura". Nos dois primeiros casos, o fator é constituído por duas variáveis: a difusão da tecnologia incorporada nas importaçóes de mercadorias e pelo estoque de investimento direto estrangeiro (IDE). De forma similar, o terceiro trabalho apresenta o nível de abertura através do IDE, no entanto, acrescenta outras três variáveis: importaçóes de bens de capital, capacidade de explorar os sistemas avançados de educação no exterior e a participação nas Cadeias Globais de Valor (CGV). Como resultado, os autores verificaram que a abertura do país ao comércio internacional não desempenha impacto tấo significativo comparativamente a outras capacidades e que quando a amostra é separada em países desenvolvidos e em desenvolvimento, verifica-se que a capacidade de absorção tende a favorecer os primeiros em detrimento ao segundo grupo.

$\mathrm{O}$ conceito mais abrangente refere-se à capacidade social -dado que é um conjunto de questóes políticas, sociais e econômicas- que apresenta a maior variabilidade de denominaçóes. Assim, para captar a dimensão econômica dessa capacidade, Fagerberg e Srholec (2005; 2016) constroem um fator ao qual designam de "Sistema Financeiro" e "Acesso ao Financiamento", respectivamente. Em tais fatores, encontram-se variáveis que representam o valor do crédito para o setor privado, a capitalização das empresas e o spread da taxa de juros. No entanto, a forma pela qual esses fatores afetaram o crescimento econômico dos países foi distinta, tendo em vista que para o primeiro trabalho, o sistema financeiro foi correlacionado positivamente com a renda de um país, enquanto para a segunda pesquisa o acesso ao financiamento náo demonstrou efeito positivo significativo sobre o crescimento. Os autores justificam que embora o acesso ao financiamento possa ser essencial para o desenvolvimento, elevaçóes no tamanho do setor financeiro para países que já possuem esse setor bem desenvolvido podem ser prejudiciais, uma vez que pode aumentar a volatilidade e "fuga" de recursos de outros setores da economia.

Para retratar a questão social, os trabalhos utilizam-se de variáveis correlacionadas à educação e à especializaçáo. Titulaçóes como "Infraestrutura do Conhecimento", "Fornecimento de Habilidades" ou apenas "Educação" são designadas para os fatores que incorporam variáveis referentes às educaçóes primária, secundária e terciária e disponibilidade de mão de obra qualificada (Fagerberg et al., 2013; Fagerberg and Srholec, 2016; 2017). De forma geral, esses fatores impactaram positivamente o desenvolvimento dos países, sendo que especificamente para Fagerberg e Srholec (2017), que aborda o conceito de desenvolvimento sustentável, a educação apresentou efeito potencializado sobre o crescimento quando as preocupações com o meio ambiente são consideradas. 
A capacidade social pode ainda ser representada por um misto de elementos sociais e políticos, resultando no fator comumente retratado por "Governança" ou "Prevalência das Normas". Dessa forma, tem-se que indicadores como o de Lei e Ordem, Independência de Tribunais, Proteção de Direitos de Propriedade, Regulação dos Negócios, Percepção de Corrupção e Extensão dos Direitos Políticos e das Liberdades Civis, quando analisados conjuntamente, tendem a ser vitais para o desenvolvimento dos países (Adelman and Morris, 1965; Kaufmann et al., 2009).

Por fim, para controlar as estimaçóes, trabalhos que pesquisam sobre a problemática do desenvolvimento incluem características sociais que são ligadas ao processo histórico dos países e que dificilmente se modificam ao longo do tempo. Fagerberg e Srholec (2008), por exemplo, inserem treze variáveis exógenas, entre elas, o registro de densidade populacional, risco de malária e registros dos depósitos de petróleo per capita. Os autores evidenciaram que diferenças na geografia, na natureza e na história importam para o crescimento e, em especial, são um obstáculo para que o sistema de inovação de um país evolua.

A exposiçáo da literatura sobre os determinantes do crescimento econômico demonstra a complexidade e importância das capacidades para o progresso econômico. A presente pesquisa espera contribuir com o estado da arte ao realizar a análise especificamente para os países em desenvolvimento, que em geral apresentam características específicas, tais como: governos muito ativos; inovaçáo que envolve o aprendizado e adaptaçáo da tecnologia estrangeira e vantagem comparativa e padrão de demanda interna diferentes dos países desenvolvidos (Nelson, 1993).

\section{Metodologia}

Para estimar os determinantes do crescimento econômico, pretende-se utilizar o método de dados em painel, onde a variável dependente é o PIB per capita $\left(P I B p c_{i j}\right)$, enquanto as variáveis explicativas serão especificadas a partir do método de análise fatorial por componentes principais. Para melhor compreensão a respeito da conjugação dessas metodologias, dividiu-se o presente tópico em três seçôes: (i) discorre-se sobre a técnica multivariada de análise fatorial, buscando definir o processo de extração dos fatores; (ii) discute-se sobre as características dos dados em painel, pormenorizando as variáveis utilizadas para a presente pesquisa; (iii) apresenta-se as fontes dos dados. 


\subsection{Análise Fatorial por Componentes Principais ${ }^{2}$}

Para um estudo relativo a análise fatorial por componentes principais, partese inicialmente da compreensão de que um fator consiste no agrupamento de variáveis originais interdependentes, de maneira que busca-se, a partir de combinaçôes lineares, estabelecer uma quantidade reduzida de fatores não correlacionados que sejam representativos do conjunto de variáveis originais (redução estrutural).

Ademais, pode-se utilizar o método de componentes principais para autenticar a validade de constructos previamente definidos, ou ainda, quando objetiva-se, a partir dos fatores, elaborar rankings indicadores de desempenho, como será realizado no presente estudo. Além disso, cabe ressaltar que os fatores ortogonais podem ser utilizados posteriormente em técnicas multivariadas que requerem ausência de multicolinearidade.

Tendo em vista o papel central que a extração dos fatores possui para a análise fatorial, há necessidade de se detalhar o processo de determinação desses, evidenciando a importância da matriz de correlaçóes de Pearson. Para tanto, considera-se especificamente para o presente estudo, um banco de dados que apresenta $50^{3}$ observaçôes associadas a cada uma das 30 variáveis quantitativas $\mathrm{X}$ (nomeadas na tabela $\mathrm{A} 1$, em anexo, e especificadas no anexo metodológico), conforme demonstrado na matriz a seguir.

$$
\left(\begin{array}{cccc}
X_{11} & X_{21} & \cdots & X_{301} \\
X_{12} & X_{22} & & X_{302} \\
& \vdots & \ddots & \vdots \\
X_{150} & X_{250} & \cdots & X_{3050}
\end{array}\right)
$$

Ressalta se que apesar de o estudo analisar 50 países em desenvolvimento, o Relatório Estatístico Anual da United Nations Organization (UN, 2017) classifica 127 países como economias pertencentes a esse grupo. O número reduzido de observaçóes deve-se ao fato de se utilizar duas bases de dados (Heritage Foundation e World Economic Forum) e abranger um longo período (2006 a 2016), resultando em perda significativa de informaçôes.

Define-se, então, a matriz de correlaçóes $\rho$, que demonstra os valores da correlação linear de Pearson entre cada par de variáveis. A combinação linear é definida num intervalo de -1 a 1 , sendo que existirá uma relação entre as variáveis quanto mais próxima do extremo essa combinaçáo estiver, constituindo-se num indicativo para a extração de um único fator. De forma

\footnotetext{
2 Seção amplamente baseada em Fávero e Belfiore (2017).

${ }^{3}$ Refere-se aos 50 países em desenvolvimento analisados na presente pesquisa.
} 
antagônica, uma correlação de Pearson muito próxima ao valor nulo, assinala que a relação linear entre as variáveis praticamente náo existe, e, como resultado, diferentes fatores podem ser construídos.

Dessa forma, a extração de fatores decorre do fato de a matriz de correlaçóes $\rho$ exibir elevados valores e que esses sejam estatisticamente significativos, e embora o exame visual já demonstre indícios de que a construção de fatores é apropriada, os testes de Kaiser-Meyer-Olkin $(\mathrm{KMO})$ e o de esfericidade de Bartlett são ferramentas estatísticas de adequação global propriamente dita da análise fatorial.

No caso da estatística KMO, esta varia entre 0 e 1 , sendo que valores acima de 0,70 indicam uma adequação global razoável da análise fatorial (Fávero e Belfiore, 2017). Pode-se articular que a principal contribuição desse teste reside no fato de que é possível captar a correlação pura entre duas variáveis, uma vez que se controla os efeitos de outras variáveis existentes na base de dados, não incorrendo, portanto, em uma falsa impressão a respeito da relação entre duas variáveis analisadas.

Sob outra perspectiva, o teste de esfericidade de Bartlett parte da comparaçáo entre a matriz de correlação de Pearson e uma matriz identidade, de tal forma que se a determinado nível de significância, as matrizes forem iguais, tem-se que as correlaçóes entre cada par de variáveis são estatisticamente iguais a zero, não sendo viável a extração de fatores.

Posteriormente a aplicação desses testes, faz-se necessário definir quantos fatores devem ser extraídos. Sabendo-se que um fator é definido como uma combinação linear das variáveis originais, pode-se estabelecer como número máximo fatores, o número de variáveis incluídas.

Os scores advindos dessa análise são essenciais quando busca-se, a partir do critério de Kaiser (raiz latente), orientar a quantidade de fatores a serem extraídos. Isso porque ao se padronizar os scores fatoriais pelos autovalores, ${ }^{4}$ seleciona-se apenas fatores correspondentes a autovalores maiores do que 1 , tendo em vista a capacidade de representar pelo menos uma variável original.

Mesmo após se determinar os fatores, é interessante calcular as intituladas cargas fatoriais, que representam as correlaçóes de Pearson entre as variáveis originais e cada um dos fatores. Nesse caso, o estudo exibirá um caráter complementar, já que se forem verificadas cargas fatoriais com valores intermediários, pode-se realizar uma rotação dos fatores já definidos, objetivando aumentar as correlaçôes entre as variáveis originais e novos fatores gerados.

Em síntese, essa rotação fatorial será realizada pelo método Varimax, com a finalidade de se redistribuir as cargas fatoriais, minimizando assim

\footnotetext{
${ }^{4}$ Os autovalores determinam a composição de cada fator ao representarem a porcentagem de variância compartilhada pelas variáveis originais.
} 
a quantidade de variáveis que exibem cargas elevadas em um único fator e, simultaneamente, maximizando-se o compartilhamento da variância em fatores associados a autovalores menores.

\subsection{Dados em painel}

Com o objetivo de analisar os determinantes do crescimento econômico, será utilizado um modelo com dados em painel. Tal escolha deve-se à possibilidade de análise da evolução temporal das variáveis de todas as unidades (países em desenvolvimento) de cross-section (Cameron and Trivedi, 2009).

O estimador utilizado será o GMM-SYS, que utiliza condiçốes de momentos adicionais, desenvolvido por Blundell e Bond (1998) com base no trabalho de Arellano e Bover (1995). Cameron e Trivedi (2009) afirmam que o referido modelo possibilita a verificação do que determina a possível persistência nas estimativas, a saber o efeito individual não observável ou as resultados passados da variável.

Cameron e Trivedi (2009) também identificaram que as variáveis defasadas em nível são instrumentos fracos quando as variáveis dependentes e explicativas apresentam forte persistência ou possuem memória longa, indicando que o valor desta variável no presente está fortemente correlacionado com seu valor no passado. Para resolver o problema, os autores propuseram a utilizaçáo de instrumentos em primeira diferença para as equaçóes em nível e instrumentos em nível para as equaçóes em primeira diferença. Esse estimador foi denominado de system GMM, enquanto o estimador de Arellano e Bond (1991) ficou conhecido como difference GMM.

Assim, o modelo a ser estimado no presente estudo será o seguinte:

$$
\begin{gathered}
\text { PIBpercapita }_{i t}=\alpha_{i t}+\beta_{1} \text { PIBpercapita }_{i t-1}+\beta_{2} \text { PIBpercapita }_{i t-2}+ \\
\beta_{3} X 1_{i t}+\beta_{4} X 2_{i t}+B_{5} X 3_{i t}+\ldots+B_{f} X N_{i t}+u_{i t} \\
i=1,2, \ldots, 50 \quad t=2006, \ldots, 2016
\end{gathered}
$$

A variável dependente é o PIB per capita, considerado como proxy de crescimento econômico dos países em desenvolvimento; $i$ representa os países em desenvolvimento $(i=50)$ e $t$ os anos a serem analisados $(t=11)$; $\alpha_{i t}$ é o intercepto da equaçãa; PIBpercapita $a_{t-1}$ e PIBpercapita PI- $_{\text {representam }}$ a variável dependente defasada em um e dois períodos, respectivamente; $X_{i t}$ representa os fatores extraídos na subseção (3.1), sendo $N$ o número de fatores; e $u_{i t}$ é o termo de erro.

A fim de avaliar se o modelo está bem ajustado e as estimativas são consistentes, utiliza-se o teste de Sargan, que permite analisar a validade 
conjunta dos instrumentos, e o teste de correlação serial, que verifica a hipótese de que os erros da equação em primeira diferença são serialmente correlacionados em primeira ordem e não autocorrelacionados em segunda ordem.

\subsection{Fonte de dados}

As informaçóes referentes as variáveis $X_{1}$ a $X_{8}$, utilizadas para a execução do presente trabalho, foram provenientes dos Índices de Liberdade Econômica, divulgados pela Heritage Foundation (2018). Complementarmente, os relatórios de competitividade global, publicados pelo World Economic Forum (WEF, 2006 a 2016), fornecem os dados relativos as variáveis $X_{9}$ a $X_{11}$.

A Heritage Foundation é uma instituição de pesquisa e educação conservadora -um think tank- caracterizada por ser um movimento conservador americano desde a sua fundação em 1973. Já o World Economic Forum, estabelecido em 1971, se define como uma organização Internacional de Cooperação Público-Privada sem fins lucrativos.

Os Relatórios são divulgados no intuito de demonstrar que há caminhos comuns a todos as regióes que desejam alcançar o desenvolvimento econômico, mesmo que esses caminhos tenham que ser adaptados às particularidades da cultura e história de cada país.

Como forma de compatibilizar os dados das duas pesquisas, restringiuse o período de análise para o presente estudo entre 2006 a 2016.

\section{Resultados}

Para maior compreensão dos resultados, esta seção se subdivide em dois tópicos. Inicialmente, realiza-se análise descritiva sobre as três capacidades consideradas no presente estudo (tecnológica, de absorção e social). No tópico posterior, discute-se a validade dessas capacidades como determinantes do crescimento econômico dos países.

\subsection{Análise descritiva das capacidades}

Diversos trabalhos buscaram captar a complexidade que permeia os conceitos de capacidade tecnológica, capacidade de absorção e capacidade social, através da análise fatorial, de forma a inserir tais capacidades na análise dos determinantes do crescimento econômico.

Especificamente para o estudo aqui realizado, as 30 variáveis, selecionadas com base na literatura, foram agrupadas em seis fatores principais 
que explicam 76\% da variância total. A estatística de Keiser-Meyer-Olkin $(\mathrm{KMO})$ e o teste de esfericidade de Bartlett, indicam a adequação global da extração desses seis fatores, sendo que o primeiro teste apresentou o valor de 0,871 .

A tabela $\mathrm{A} 1^{5}$ demonstra as cargas das variáveis retidas em cada fator após realizadas as rotaçóes através do método Varimax. As cargas fatoriais são os coeficientes de correlação entre as variáveis (representadas nas linhas) e fatores (indicados nas colunas), e fornecem a base para nomear e interpretar os fatores extraídos.

Dessa forma, o primeiro fator apresenta uma estreita correlação com indicadores de pesquisa e desenvolvimento, sendo entấo associado à capacidade tecnológica. No entanto, por englobar igualmente variáveis que refletem a qualidade da educação e treinamento, esse fator foi denominado de Sistema Nacional de Inovaçáo, dado que se aproxima muito da ideia da interação entre aprendizagem e inovação apresentada por Fagerberg e Srholec (2017).

O referido fator, como já evidenciado pela literatura, desempenha papel vital para o crescimento dos países, sendo o foco para o presente estudo. Dessa forma, buscando atribui-lhe maior destaque na análise descritiva, apresenta-se na Figura 1 a relação média entre o logaritmo do Produto Interno Bruto (PIB) per capita e o Sistema Nacional de Inovação (SNI) dos países em desenvolvimento, para o período de 2006 a 2016.

\section{Figura 1}

\section{Relação entre PIB per capita e SNI para os países em desenvolvimento, 2006-2016}

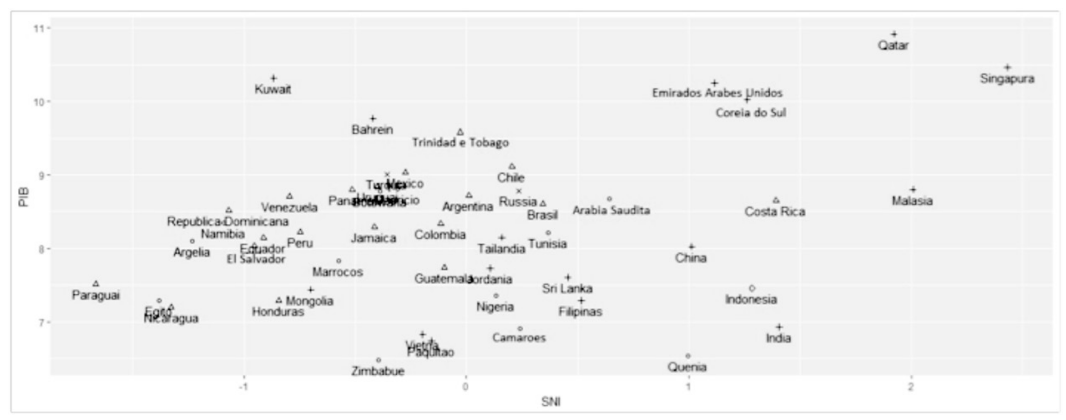

* Nota: Os símbolos presentes na parte superior de cada país designam o continente a qual pertence, sendo que: $\diamond$ Oceania, + Ásia, $\circ$ África, x Eurásia e $\Delta$ América.

**Nota: A figura apresenta na vertical a média do logaritmo do Produto Interno Bruto (PIB) per capita no período de 2006 a 2016. Na horizontal tem-se a média do fator intitulado Sistema Nacional de Inovaçáo (SNI) para o período de 2006 a 2016.

Fonte: elaboração própria, com base nos dados da Heritage Foundation (2018) e do World Economic Forum (WEF, 2006 a 2016), valendo-se do software SPSS 20 (2012).

${ }^{5}$ A tabela A1 encontra-se no Anexo A. 
Observa-se que os países que se encontram em um ponto mais elevado verticalmente apresentam PIB per capita maior e, de forma análoga, aqueles que se localizam mais próximos ao extremo direito da figura, possuem um Sistema de Inovação mais avançado. Nesse sentido, há países que apresentam elevado PIB per capita para um SNI de baixa qualidade, como os dois países ricos em recursos naturais (produtores de petróleo) pertencentes ao continente asiático (Kuwait e Bahrein). De forma contrária, Quênia, Indonésia e Índia exibem um Sistema de Inovação muito aperfeiçoado para o seu nível de PIB per capita. Nesse sentido, mesmo que aparentemente surpreendente, Quênia, apesar de indicadores sociais relativamente ruins, vêm assumindo o posto de economia mais competitiva na África Oriental, ao desenvolver um dos centros de inovação mais fortes da regiáo (WEF, 2018).

Especificamente, os países que possuem características semelhantes às da Índia, os denominados BRICS, não são totalmente homogêneos na relação entre renda e sistema de inovação. Isso se evidencia, uma vez que a China, de forma equivalente à Índia, demonstra possuir um SNI evoluído para sua renda per capita, enquanto a Rússia, Brasil e África do Sul apresentam um nível de SNI mais compatível com seus respectivos PIBs per capita.

Por fim, pode ser ainda verificado que a relação entre renda per capita e o SNI se apresenta de forma semelhante para alguns países, onde podese observar uma sobreposição parcial entre essas unidades. ${ }^{6}$

O segundo fator reflete vários aspectos relacionado à capacidade social, como os direitos de propriedade, integridade do governo e liberdade financeira, sendo entâo denominado "governança". Para esse fator, a exemplo do primeiro, traçou-se sua relaçáo média com o PIB per capita, tendo em vista o entendimento da importância positiva da governança sobre o crescimento dos países.

A principal discussão que advém da Figura 2 diz respeito à diferença entre dois países pertencentes ao mesmo continente, Venezuela e Chile. Apesar do nível de renda per capita ser semelhante entre esses países, com tendência levemente acentuada para o Chile, sua relação com a governança se mostra extremamente antagônica. Dessa forma, enquanto o Chile apresenta o maior nível no que se refere à liberdade nos mais diferentes âmbitos, a Venezuela exibe intensa desvantagem nesse aspecto.

Discute-se esse cenário tendo como base o ranking de competitividade, que engloba questóes relacionadas à governança dos países (WEF, 2016). A América Latina, sendo muito heterogênea, apresenta grande variação no ranking de seus países, sendo que o Chile era o país latino-americano com

\footnotetext{
${ }^{6}$ Observa-se três grupos nessa situação: (i) Turquia, Uruguai, Botswana, Panamá, Maurício e México; (ii) Egito e Nicarágua; (iii) Vietnã e Paquistão.
} 


\section{Figura 2 \\ Relação entre PIB per capita e Governança para os países em desenvolvimento, 2006-2016}

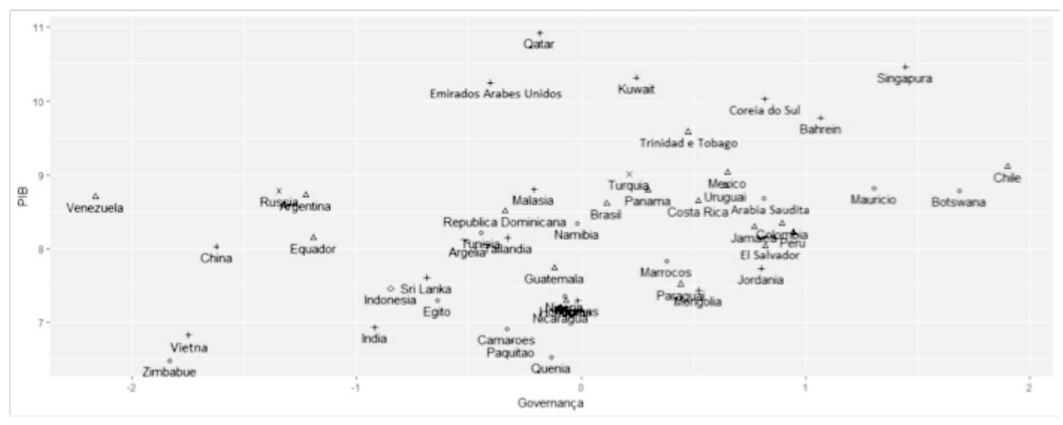

*Nota: Os símbolos presentes na parte superior de cada país designam o continente a qual pertence, sendo que: $\diamond$ Oceania, + Ásia, $\circ$ África, x Eurásia e $\Delta$ América.

**Nota: A figura apresenta na vertical a média do logaritmo do Produto Interno Bruto (PIB) per capita no período de 2006 a 2016. Na horizontal tem-se a média do fator intitulado Governança para o período de 2006 a 2016.

Fonte: Elaboração própria, com base nos dados da Heritage Foundation (2018) e do World Economic Forum (WEF, 2006 a 2016), valendo-se do software SPSS 20 (2012).

melhor classificação $\left(33^{\circ}\right)$, enquanto a Venezuela ocupava o último lugar $\left(130^{\circ}\right)$, devido, dentre outros fatores, ao enfraquecimento das suas instituiçôes, impulsionado por questôes ligadas a ética e corrupção.

Analisando-se as duas figuras, é importante destacar o papel de destaque de Singapura, um país que apresenta elevado nível de PIB per capita e fatores de sistema de inovação e governança bem consolidados. Esse resultado é discutido no relatório do WEF (2016), em que Singapura, além de ter como pilar a valorização do treinamento da mão de obra, possui ambiente macroeconômico estável, com finanças públicas saudáveis, dispondo ainda de instituiçóes públicas transparentes e altamente eficientes.

O terceiro fator é particularmente ligado a incidência e impacto de doenças, sendo, consequentemente, denominado de "Ecologia das doenças". Como já exposto, usualmente os estudos utilizam apenas uma variável ao invés de se calcular o fator que represente as doenças, sendo inserida como controle nos modelos econométricos. Analisando-se a relação média do PIB per capita com esse terceiro fator, tem-se que essa relação é especialmente alarmante para cinco países do continente africano ${ }^{7}$, sendo que Zimbábue e Quênia figuram com o pior cenário.

O quarto fator, apesar de se correlacionar com a mortalidade infantil, foi nomeado de Educação, tendo em vista a presença expressiva das taxas

${ }^{7}$ Os cinco países são: África do Sul, Namíbia, Botswana, Zimbábue e Quênia. 
de matrícula referentes aos três níveis de ensino. Novamente, cinco $^{8}$ países africanos se distinguem negativamente dos demais. Contudo, pela primeira vez, a Índia também evidencia-se desfavoravelmente em relaçáo ao fator. A cultura, especialmente o Sistema de Castas, pode ser um dos aspectos que colabora para tal resultado, tendo em vista as funçóes já atribuídas a cada indivíduo, de acordo com a posição social que ocupam, bem como ao papel da mulher na sociedade indiana.

O quinto e sexto fatores expressam questóes que em geral estáo ligados ao governo: infraestrutura e gastos públicos, respectivamente. $\mathrm{O}$ primeiro reflete a estrutura necessária, mas não suficiente, para que um país ganhe competitividade frente aos seus pares, através da redução dos custos, por exemplo. Já o segundo busca captar o impacto das contas públicas sobre o crescimento, evidenciando uma discussão já muito presente na literatura. ${ }^{9}$ Analisando-se a relação do PIB per capita médio com cada um desses dois fatores, o resultado mais importante a ser ressaltado diz respeito ao fator de Infraestrutura, tendo em vista que tanto o Brasil quanto a Costa Rica, países com uma renda per capita considerável, exibem pior relação com esse fator frente às demais nações.

Esses seis fatores ponderados resultaram no ranking de capacidades ${ }^{10}$ dos países em desenvolvimento, podendo então ser observada a evolução dessas naçóes para os âmbitos abordados no período de 2006 a 2016. A constatação mais evidente consiste na persistência de Singapura na primeira posição e, no extremo oposto, Zimbábue apresentando-se com o menor nível de capacidades. Tal resultado vai parcialmente ao encontro do ranking de competividade do WEF (2018), para o período de 20162017, tendo em vista que Singapura ocupa, em ambos os estudos, a favorável posição de destaque ${ }^{11}$. No entanto, para esse ranking, Zimbábue é superado, de forma negativa, por Nigéria e Venezuela.

Concluiu-se, então, que Singapura apresenta-se com uma conjuntura estruturada, de forma que a torna superior às demais naçóes em desenvolvimento mesmo quando se altera as variáveis representativas da realidade. Já para Zimbábue, a escolha da inclusão de determinadas variáveis parece impactar no seu desempenho perante a outras naçóes.

De forma geral, os demais países aqui analisados também apresentaram certa estabilidade em relação a sua posição no ranking. Contudo, o Brasil se destacou por sua mudança descendente, já que no ano de 2006 ocupava a $11^{\circ}$ colocaçáo e passou para $32^{\circ}$ posição em 2016 , sendo que a maior queda ocorreu no ano de 2014. Como segundo a Fundação

\footnotetext{
${ }^{8}$ Os cinco países são: Nigéria, Paquistão, Camarôes, Quênia e Zimbábue.

${ }^{9}$ Ver Bose et al. (2007), Bonelli (2009); Rodrigues e Teixeira (2010) e Neduziak e Correia (2017).

${ }^{10}$ Ver tabela A2 no Anexo A.

${ }^{11}$ Salienta-se que o ranking de competitividade engloba 138 países, de forma que para a comparação, excluiu-se os que não foram compatíveis com o presente estudo.
} 
Getúlio Vargas (FGV, 2017), a recessão doméstica compreendeu o período de 2014 a 2016, parece razoável presumir que a trajetória de deterioração das capacidades brasileiras foi agravada pela crise. No entanto, se faz necessário um estudo mais aprofundado a este respeito.

Por fim, agrupando-se os dez primeiros colocados do ranking nos anos de 2006 e 2016 e os classificando de acordo com o continente a que pertencem, observa-se que os países asiáticos predominam, representando $70 \%$ desse grupo. Em seguida, 20\% das naçôes que se destacam por suas capacidades é formada por países do continente americano e há apenas uma país africano nesse seleto grupo.

Em contrapartida, o grupo formado pelos dez últimos países do ranking exibe uma mudança na sua composição quando se compara os dois anos. Em 2006, esse grupo é formado por cinco países pertencentes ao continente americano e cinco naçóes africanas. No entanto, em 2016, os países africanos passam a ser predominantes (mantendo-se cinco países), enquanto os países americanos compóem $40 \%$ desse grupo, tendo em vista que o Paquistão passa a figurar como o único país asiático com baixo nível de capacidades comparativamente a seus pares.

Dessa maneira, quando se considera as capacidades, tem-se uma grande disparidade entre o continente asiático e africano, enquanto o continente americano se distribui de forma mais semelhante nos dois extremos.

A partir dessa definição e análise dos fatores, no seguinte tópico apresenta-se a abordagem econométrica, de forma a verificar a relação entre esses fatores e o desenvolvimento econômico.

\subsection{As capacidades como determinantes do crescimento econômico}

Ao considerar a endogeneidade existente entre o crescimento econômico e as capacidades, utilizou-se a metodologia de dados em painel dinâmico, onde os instrumentos são as próprias variáveis defasadas em dois lags. Para comprovar a validade dos instrumentos, é essencial que sejam realizados os testes de Sargan e de Autocorrelaçáo serial. Os resultados são exibidos na tabela 1 .

Assume-se um risco máximo de $10 \%$ de cometer o erro tipo um, que é de rejeitar a hipótese nula e estar equivocado. $\mathrm{O}$ resultado, a partir do teste de Sargan, aponta para a validade dos instrumentos dos modelos. Para o teste de Autocorrelação serial, os valores representam as probabilidades para a primeira e segunda defasagem do termo de erro, respectivamente. De acordo com Da Cruz Ourives (2006) e Rocha e Oreiro (2008), a não rejeição da hipótese nula do teste referente à segunda defasagem garante a consistência do modelo estimado, condição que foi satisfeita. 
Tabela 1

Teste de validade dos instrumentos

\begin{tabular}{cc}
\hline Teste de Sargan & Teste de Autocorrelação \\
\hline 0.5936 & 0.0262 \\
& 0.3362
\end{tabular}

Fonte: Elaboração própria, com base nos dados da Heritage Foundation (2018) e do World Economic Forum (WEF, 2006 a 2016), valendo-se do software STATA (2015).

Dessa forma, prosseguiu-se com a estimaçáo do modelo dinâmico e o resultado é apresentado na tabela 2 .

\section{Tabela 2}

\section{Determinantes do desenvolvimento econômico}

\begin{tabular}{lccc}
\hline \multicolumn{1}{c}{ Variáveis } & Coeficientes & Desvio Padrão & $Z$ \\
\hline Constante & $0.2590^{*}$ & 0.0256 & 10.10 \\
PIBpercapita $_{t-1}$ & $1.1167^{*}$ & 0.0069 & 162.93 \\
PIBpercapita $_{t-2}$ & $-1.1462^{*}$ & 0.0067 & -21.74 \\
Sistema de Inovação $_{\text {Governança }}$ & $0.0174^{*}$ & 0.0010 & 18.06 \\
Ecologia das Doenças & $0.0089^{*}$ & 0.0011 & 07.96 \\
Educação & $-0.0133^{*}$ & 0.0013 & -09.93 \\
Infraestrutura & 0.0003 & 0.0018 & 00.19 \\
Tamanho do Estado & $0.0142^{*}$ & 0.0012 & 11.77 \\
\hline
\end{tabular}

Fonte: Elaboração própria, com base nos dados da Heritage Foundation (2018) e do World Economic Forum (WEF, 2006 a 2016), valendo-se do software STATA (2015).

Como pode ser verificado, a principal variável de interesse, o sistema de inovação, apresenta o maior coeficiente, sendo significativo e positivo. Esse resultado vai ao encontro do exposto por Fagerberg e Srholec (2005; 2008), Fagerberg et al. (2007; 2017). Diante disso, para os países em desenvolvimento, fortalecer o SNI é o principal caminho para o crescimento econômico. No entanto, realizar tal feito não é simples, já que como ressaltado, esse fator engloba a valorização da pesquisa e desenvolvimento através de investimento e disponibilidade de mão de obra especializada. Dessa forma, são necessárias políticas de longo prazo que visem ofertar educação e treinamento de qualidade.

Nesse sentido, cabe ressaltar a variável intitulada de educação, pois ela náo impactou de forma significativa no crescimento dos países. Ao contrário do que inicialmente se deduz, esse resultado não é oposto a 
orientação de políticas públicas anteriormente citada, tendo em vista que esse fator é composto por taxas de matrículas, implicando que o ensino e especialização se limitou a quantidade, não sendo verificado, portanto, a qualidade educacional.

Tal análise explica a razão de variáveis como "qualidade do sistema educacional" apresentarem correlaçáo com o Sistema Nacional de Inovação e não com o fator denominado Educação. Evidencia-se, portanto, um cenário alarmante para os países em desenvolvimento, uma vez que o capital humano, imprescindível para o progresso sustentado, parece não estar recebendo a qualificação mínima necessária.

De forma a reforçar a importância do capital humano para o crescimento, tem-se que o coeficiente do fator atrelado a saúde dos indivíduos, denominado Ecologia das Doenças, foi significativo e negativo, como no trabalho de Fagerberg e Srholec (2008). Consequentemente, os países em desenvolvimento devem buscar implementar políticas sinérgicas visando a educação de qualidade e, paralelamente, amenizar os problemas de saúde pública.

No entanto, a referida oferta de educação e saúde pública de qualidade encontra obstáculos quando aplicada a um país no qual os governantes são movidos pelo interesse próprio. Nesse sentido, a boa governança figura-se como essencial para o progresso de qualquer país. Esse fato é verificado no modelo econométrico, uma vez que o fator de governança impactou de forma positiva e significativa o crescimento dos países. Tal constatação é corroborada pelos estudos de Adelman e Morris (1965), Fagerberg et al. (2007) e Kaufmann et al. (2009).

Um governo que estabeleça como objetivo o crescimento pode ainda garantir progresso sustentado ao orientar suas açóes para a elevaçáo da competitividade do país. Um caminho possível para que isso aconteça é o investimento em infraestrutura. Como demonstrado através do resultado, o coeficiente do fator que engloba a infraestrutura aérea, portuária e a qualidade das rodovias foi significativo e positivo para o desenvolvimento dos países, indo ao encontro do exposto por Ferraz et al. (1996).

Por fim, numa concepção mais ampla do que a do investimento em infraestrutura, a interferência do governo na economia, através da elevação dos gastos (Tamanho do governo), figura-se como um significativo determinante do crescimento dos países, indo, portanto, ao encontro da Teoria Keynesiana. No entanto, essa constatação deve ser ponderada, ${ }^{12}$ tendo em vista a complexidade das contas nacionais. ${ }^{13}$

\footnotetext{
${ }^{12}$ Para mais detalhes sobre a complexidade das contas públicas, ver System of National Accounts 2008 (OECD et al., 2009).

${ }^{13}$ Bose et al. (2007), por exemplo, ao analisar 30 países em desenvolvimento, concluíram que a despesa agregada não tem efeito sobre o crescimento dessas naçóes, ao passo que ao desagregá-la, a despesa com educação ou projetos de capital foram positivos e significativos.
} 
Concluiu-se, a partir das discussóes realizadas, que os resultados apresentados vão ao encontro do que é exposto na literatura atualmente, de forma que o sistema da inovação figura-se como o principal determinante para o crescimento econômico, mesmo quando o foco são apenas os países em desenvolvimento.

\section{Conclusóes}

Há na literatura dificuldade em estabelecer um consenso sobre a definição e mensuraçáo do desenvolvimento econômico, tendo em vista que esse tema apresenta grande abrangência ao englobar questóes relacionadas às mudanças econômicas, sociais, culturais e políticas.

Considerando crescimento e desenvolvimento econômico como fenômenos similares, o presente estudo atribui ao conhecimento papel preponderante. Dessa forma, através da análise fatorial, extraiu-se seis fatores que representam as capacidades necessárias para que um país possa se desenvolver, adquirir e implementar uma nova tecnologia.

Ao incorporar esses seis fatores na estimação de modelo com dados em painel dinâmico, constatou-se que a hipótese inicialmente adotada, de que a sistema de inovação é o principal fator para o progresso econômico dos países em desenvolvimento, foi verificada.

Ademais, concluiu-se que os coeficientes dos fatores denominados de governança, infraestrutura e tamanho do governo foram significativos e positivos para o desenvolvimento dos países, enquanto o parâmetro relacionado com a variável ecologia das doenças foi significativo e negativo. No entanto, a variável educação não foi significativa para explicar o desenvolvimento dos países.

A partir desse cenário, ressalta-se, em especial, a importância da qualificação do capital humano, uma vez que há indícios de que a elevação da taxa de matriculas nos três níveis de ensino não esteja afetando a renda per capita dos países, o que direciona ao questionamento sobre a qualidade da especialização oferecida nas naçóes em desenvolvimento.

Mais precisamente, há indícios que a qualidade dessa especialização é incompatível com a necessidade das empresas inovadoras. Sendo assim, sugere-se uma política de longo prazo, em que haja o fortalecimento da educação básica -por meio de maior valorização, estrutura e capacitação dos profissionais do ensino-, aliado a uma reformulação do ensino médio e superior capaz de ofertar conhecimentos e habilidades harmônicos à demanda das empresas competitivas. Dessa forma, o sistema educacional, em parceria com as empresas, seria responsável por introduzir as novas técnicas/conhecimento impulsionadoras do progresso econômico. 
Por fim, dado que o presente estudo confirmou a hipótese de que o Sistema Nacional de Inovação é o principal determinante do crescimento econômico, abre-se caminho para que futuras pesquisas detalhem as particularidades desse fator de elevada complexidade. A principal contribuição aqui foi trabalhar com países em desenvolvimento, por apresentarem características que os diferenciam substancialmente dos desenvolvidos. Contudo ainda há grande diferenciação entre as nações da amostra. Dessa maneira, com auxílio do ranking, exibido no anexo, seria interessante realizar cortes de análise, objetivando realizar uma descrição/comparação entre os países. Isso possibilitaria apontar diferenças e semelhanças entre as naçóes em desenvolvimento e seus Sistemas de Inovação.

Ainda, sugere-se a atualização da presente pesquisa, com a inclusão de novas variáveis, já que a pandemia do vírus SARS-CoV-2 afetou o cenário econômico mundial, com reflexo sobre as políticas monetárias, comerciais e fiscais dos países. Nesse sentido, o impacto sobre as capacidades das naçóes, em especial das em desenvolvimento que naturalmente apresentam instituições frágeis, merece grande atenção.

Nesse aspecto, Arbix (2020), analisando especificamente o caso brasileiro, afirma que a pandemia do vírus SARS-CoV-2 terá graves consequências sobre o frágil sistema de inovação do país, fruto, dentre outros fatores, da baixa qualidade educacional, o que tende a comprometer a recuperação da economia e a necessária reorganização social. Nesse sentido, Leão e Giesteira (2020) sugerem a construção de capacidades produtiva, tecnológica e inovadora orientadas por missóes e demandas de Estado, o que aumentaria as chances de que o país responda mais efetivamente aos efeitos da pandemia e de outras crises que podem acometê-lo. 


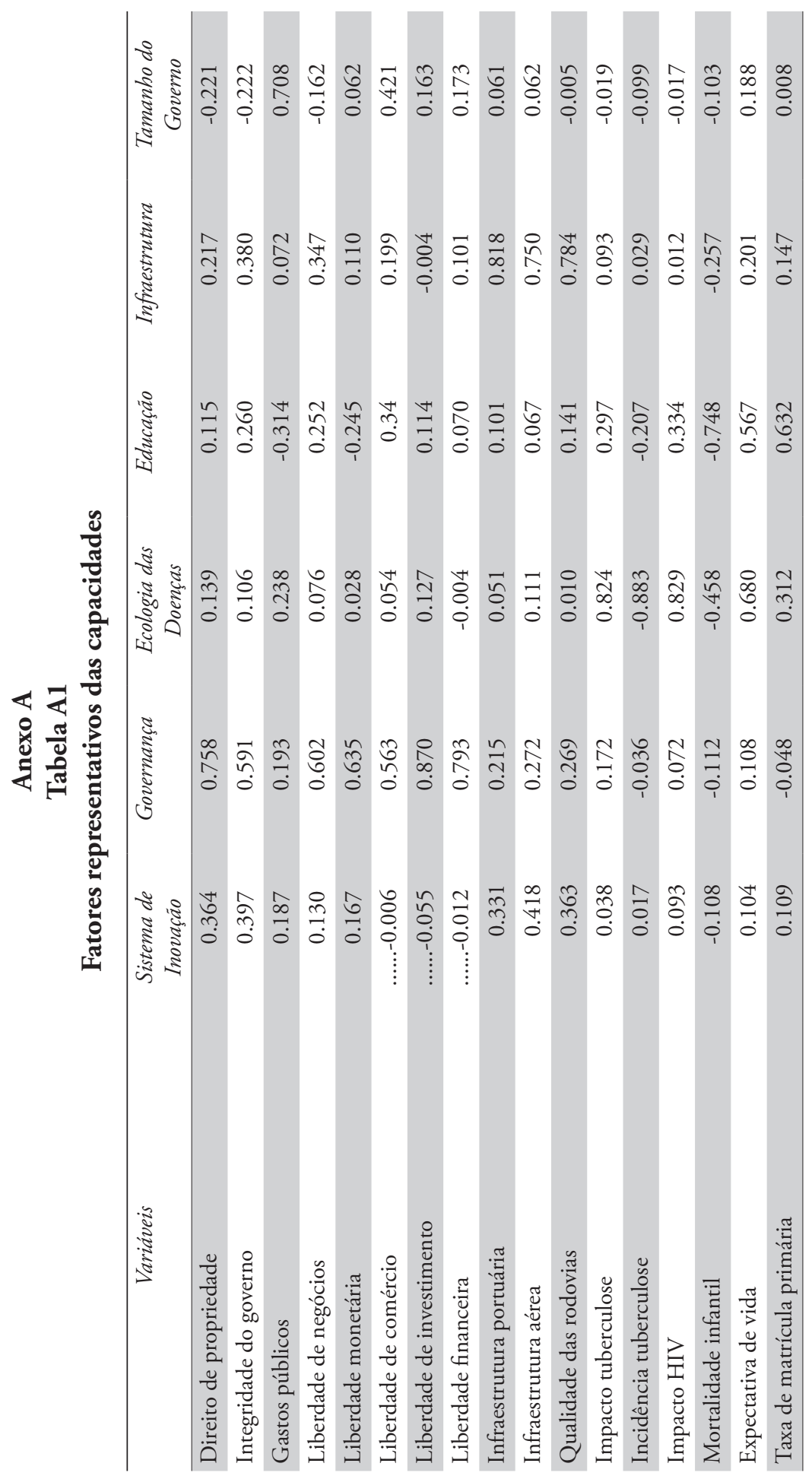




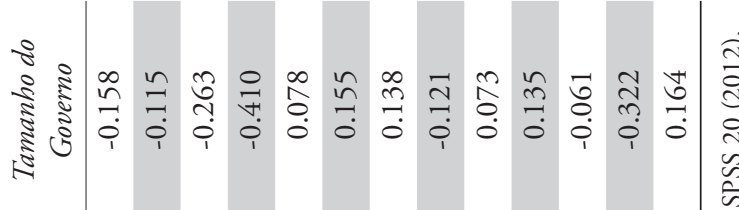

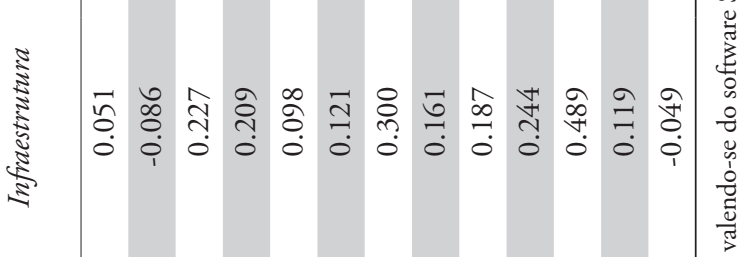

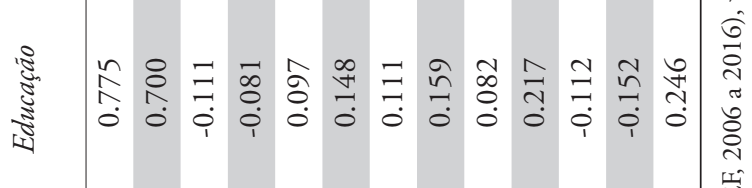

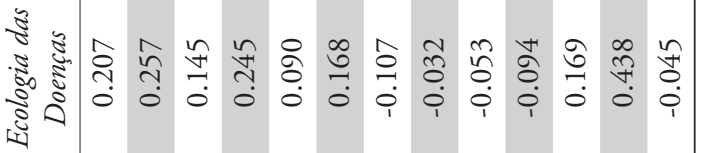

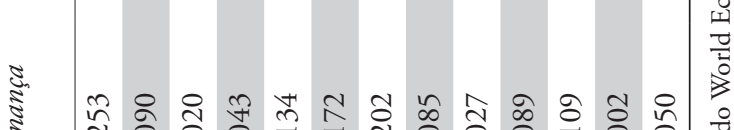

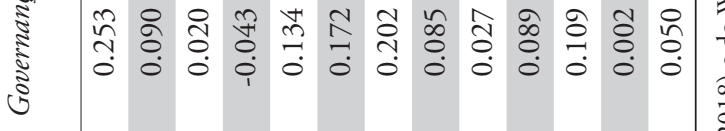

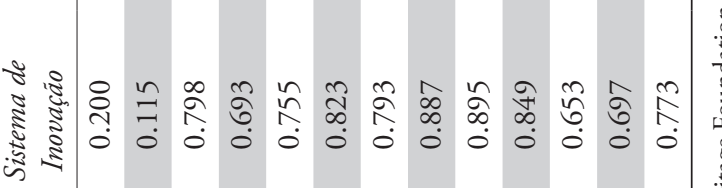

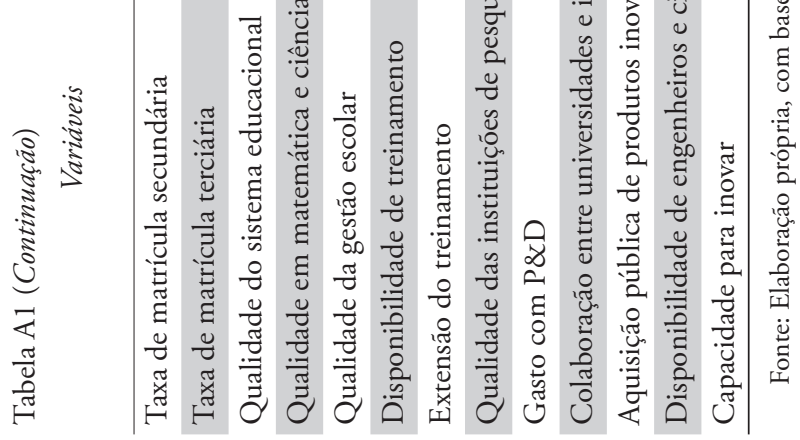




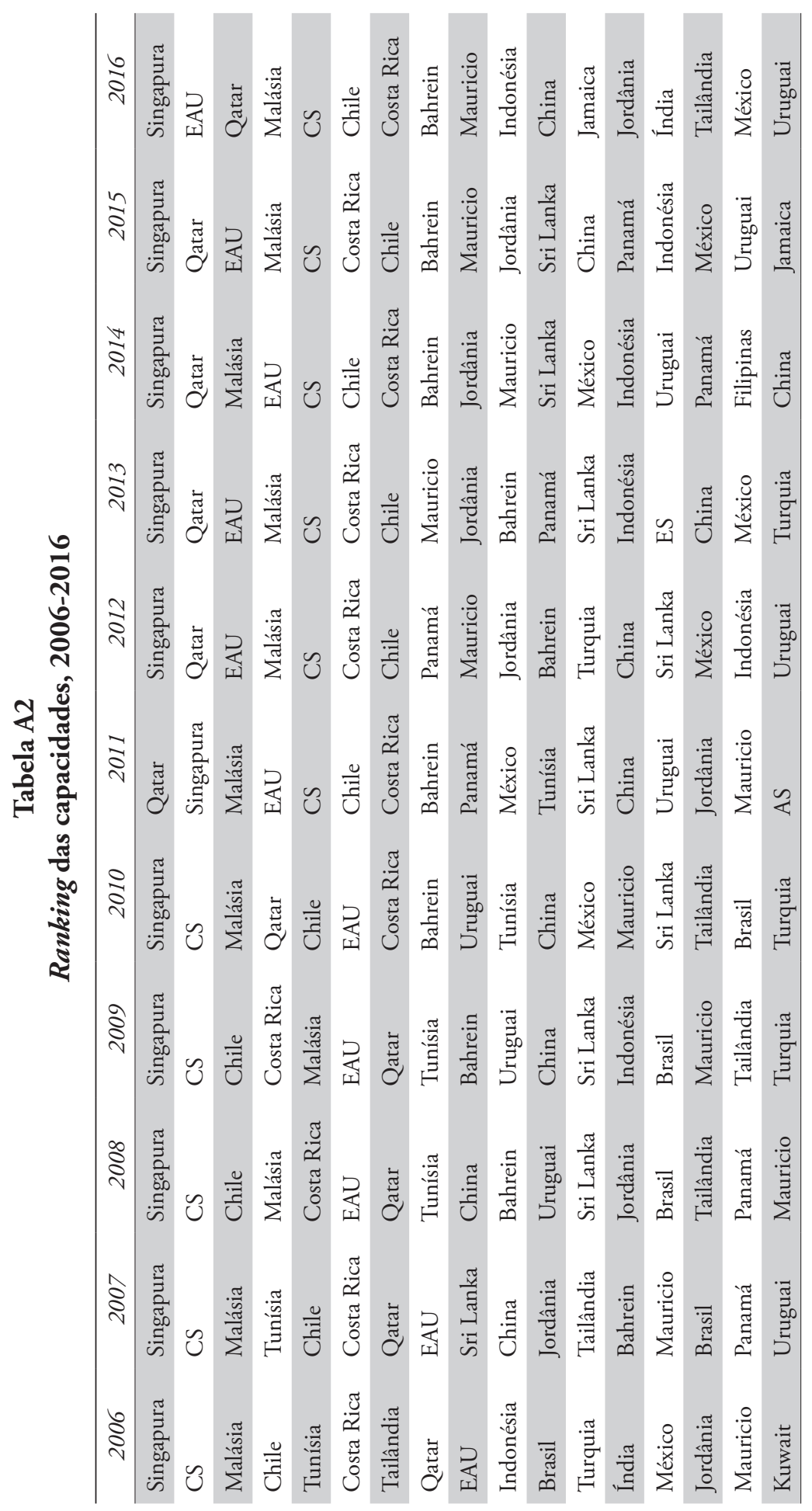




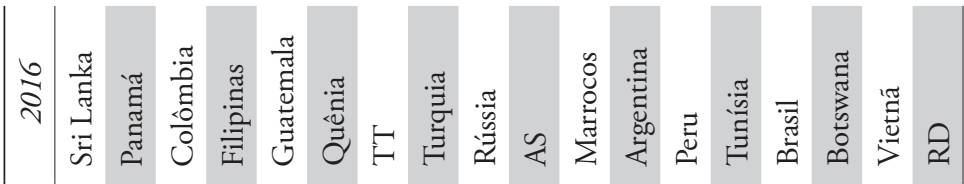

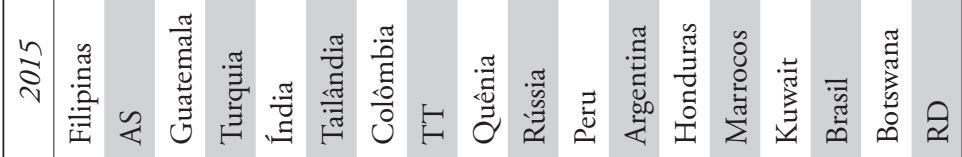

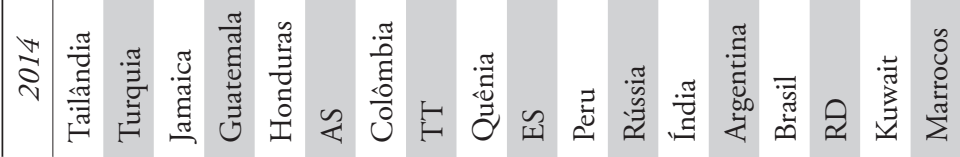

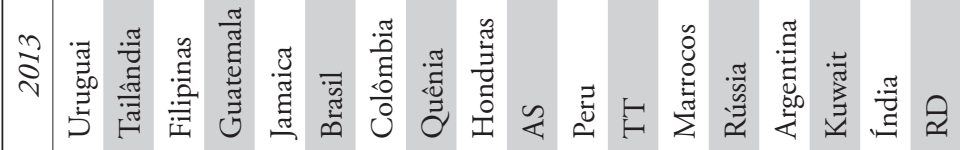

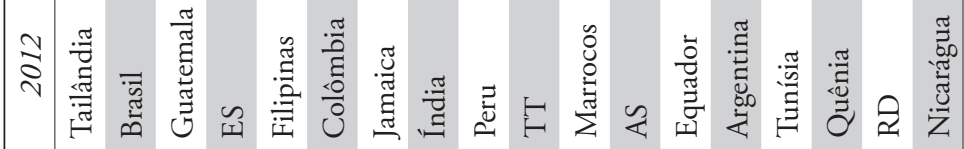

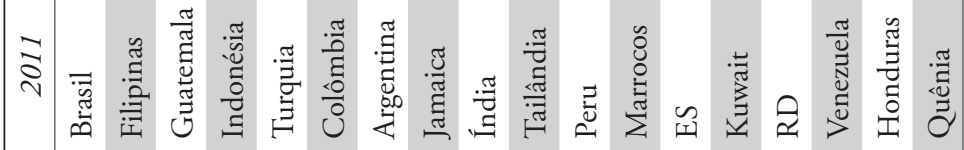

$$
\begin{aligned}
& \text { ง }
\end{aligned}
$$

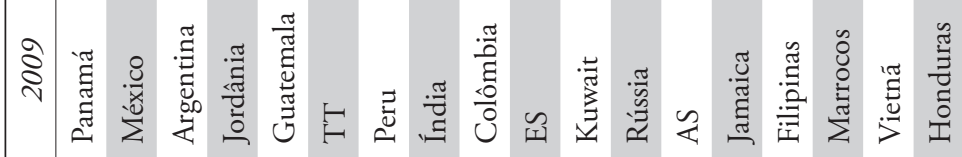

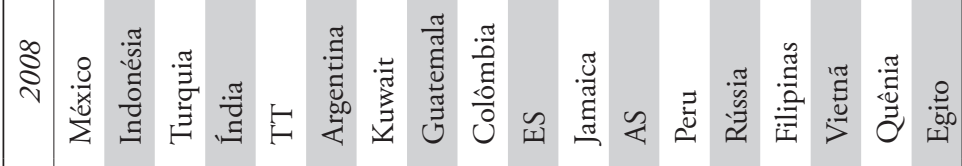

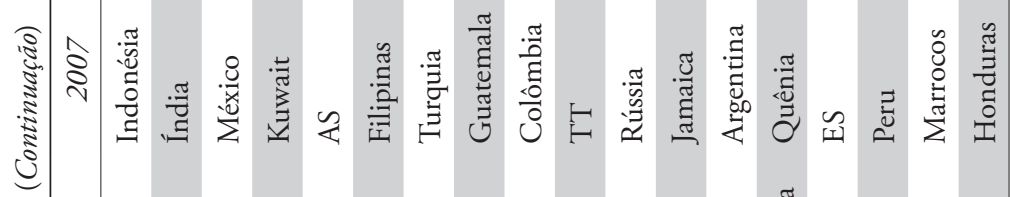

$$
\begin{aligned}
& \text { 离 }
\end{aligned}
$$




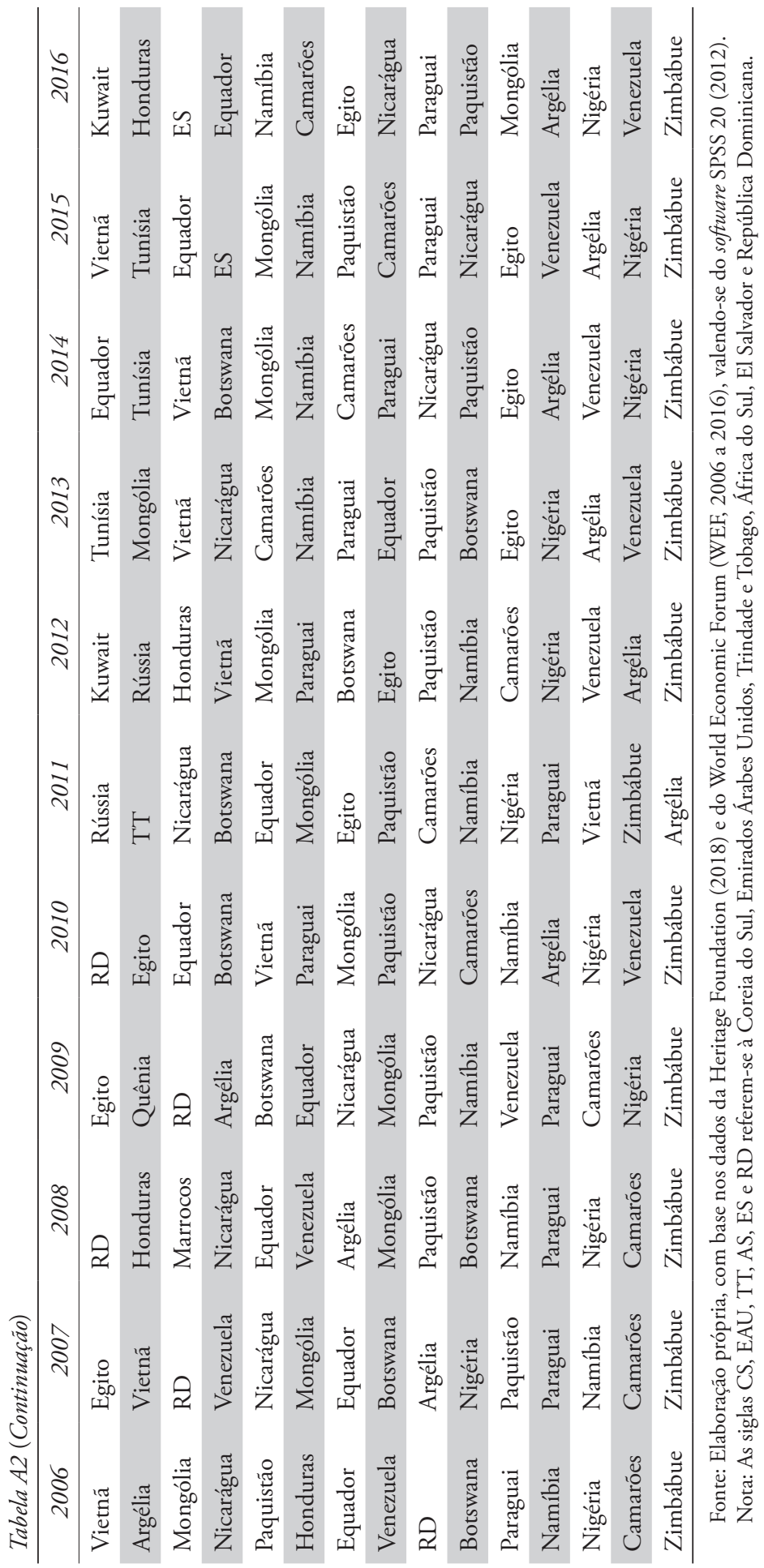




\section{Anexo metodológico}

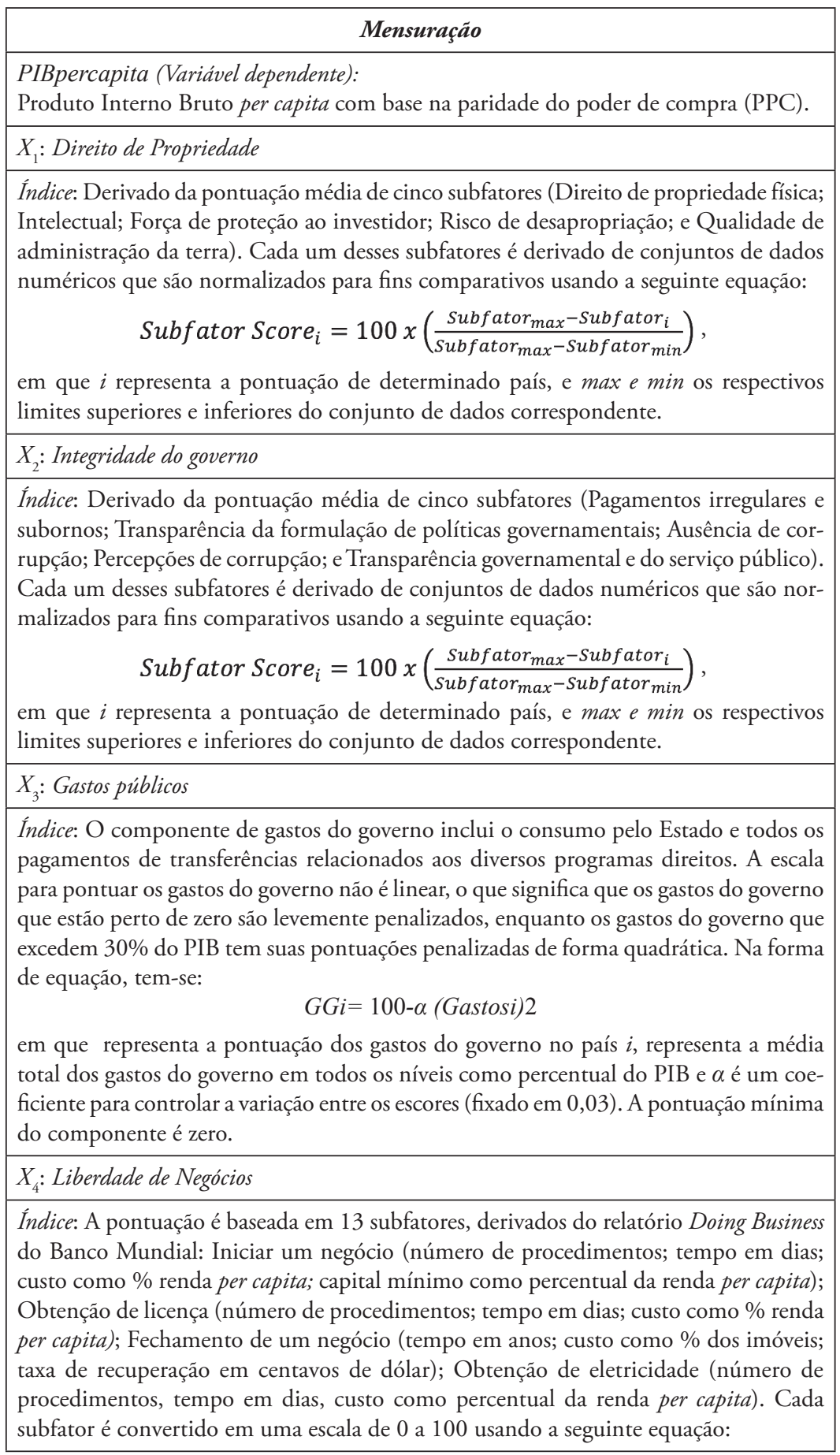


(Continuação)

$$
\text { Subfator } \text { Score }_{i}=50 \times\left(\frac{\text { Subfator }_{\text {media }}}{\text { Subfator }_{i}}\right)
$$

que representa a razão dos dados do país para cada subfator em relação à média.

\section{$X_{5}$ : Liberdade monetária}

Índice: A liberdade monetária combina uma medida de inflação com uma avaliação de várias atividades governamentais que distorcem os preços. A pontuação do componente de liberdade monetária baseia-se em dois subfatores: a taxa média ponderada de inflação para os últimos três anos e um julgamento qualitativo sobre a extensão da manipulação governamental dos preços através de controles diretos ou subsídios. A taxa média ponderada de inflação dos últimos três anos serve como o principal insumo em uma equação que gera o escore base para a liberdade monetária. As duas equaçóes usadas são:

$$
\text { Taxa media de inflacao }{ }_{i}=\theta_{1} \text { inflacao }_{i t}+\theta_{2} \text { inflacao }_{i t-1}+\theta_{3} \text { inflacao }_{i t-2}
$$

Liberdadi Monetaria $_{i}=100-\alpha \sqrt{ }$ Taxa $_{\text {media de }}$ inflaca $_{i}-$ PC $_{\text {penaleidade }}$ em que $\theta_{1}$ a $\theta_{3}$ representam três números que somam 1 e são exponencialmente menores em sequência; inflação $o_{i t}$ é o valor absoluto da taxa de inflação anual no país $i$ durante o ano mensurado, medida pelo Índice de Preços ao Consumidor; $\alpha$ representa um coeficiente que estabiliza a variância dos escores; e a penalidade de controle de preços (PC) é um valor atribuído de 0 a 20 pontos de penalidade com base na extensão dos controles de preços. A forma funcional convexa (raiz quadrada) é utilizada para criar separação entre países com baixas taxas de inflação.

$X_{6}:$ Liberdade de comércio

Índice: A liberdade comercial é uma medida composta por dois subfatores: a taxa tarifária média ponderada do comércio e a avaliação qualitativa de barreiras não tarifárias (NTBs). Expressando em forma de equação:

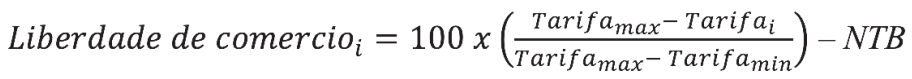

em que $\max$ e $\min$ representam respectivamente os limites superiores e inferiores das tarifas (\%), sendo que a tarifa mínima é de $0 \%$ e o limite superior foi fixado em $50 \%$. representa a taxa tarifária média ponderada (\%) no país $i$.

Para determinar a extensão das NTBs no regime de política comercial de um país utilizou-se as informaçóes como: Restriçóes de quantidade (cotas de importação, restriçôes voluntárias à exportação; embargos e proibiçóes de exportação); Restriçôes regulatórias (licenciamento, normas sanitárias e fitossanitárias); Restriçôes alfandegárias (requisitos de depósito antecipado, procedimentos de avaliação aduaneira); e Intervenção direta do governo (subsídios e outros auxílios, políticas industriais governamentais).

$X_{7}$ : Liberdade de investimento

Índice: Formado por sete formas de restriçóes regulatórias impostas ao investimento, a saber: Tratamento nacional do investimento estrangeiro; Código de investimento estrangeiro; Restriçôes à propriedade da terra; Restriçôes de investimento setorial; Desapropriaçáo de investimentos sem compensação justa; Controles cambiais; e Controles de capital.

Os pontos são deduzidos da pontuação ideal de 100 para cada uma das restriçóes. Um máximo de 20 pontos adicionais pode ser deduzido por problemas de segurança, falta 


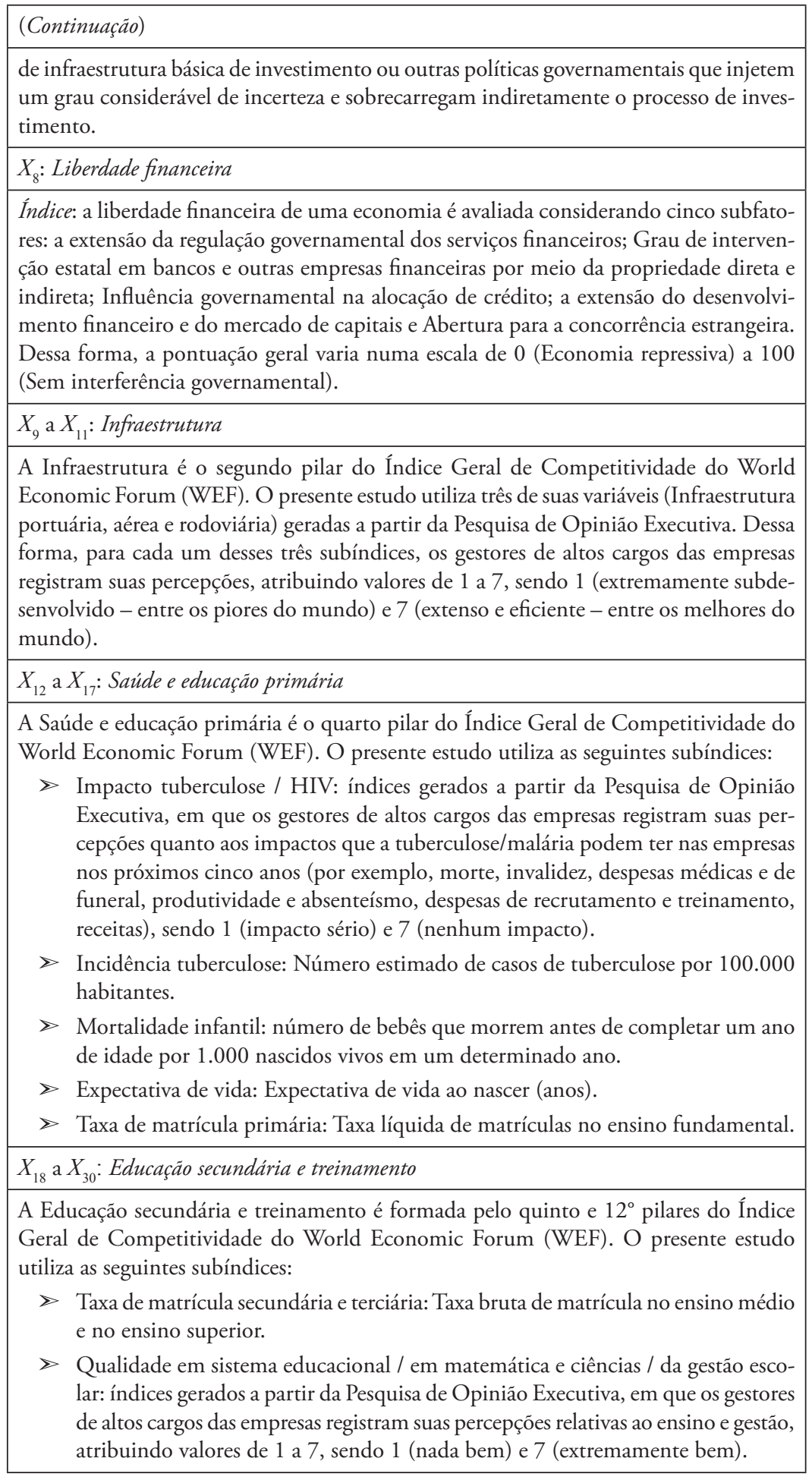


(Continuação)

$\gg$ Disponibilidade de treinamento: índice gerado a partir da Pesquisa de Opinião Executiva, em que os gestores de altos cargos das empresas registram suas percepçóes sobre a disponibilidade de serviços de formação profissional de alta qualidade no seu país, sendo 1 (não disponível) e 7 (amplamente disponível).

$\gg$ Extensão do treinamento: índice gerado a partir da Pesquisa de Opinião, em que os gestores registram suas percepçóes sobre até que ponto as empresas investem em treinamento e desenvolvimento de funcionários, sendo 1 (de forma alguma) e 7 (em grande medida).

$\gg$ Qualidade das instituições de pesquisa: índice gerado a partir da Pesquisa de Opinião, em que os gestores registram suas percepçóes sobre a qualidade das instituiçóes de pesquisa científica no país, sendo 1 (extremamente pobre - entre os piores do mundo) e 7 (extremamente bom - entre os melhores do mundo).

$\gg$ Gasto com P\&D: índice gerado a partir da Pesquisa de Opinião, em que os gestores registram suas percepçóes sobre o investimento das empresas em pesquisa e desenvolvimento (P\&D), sendo 1 (não investe) e 7 (investe fortemente).

$\gg$ Colaboração entre universidades e indústrias: índice gerado a partir da Pesquisa de Opinião, em que os gestores registram suas percepções sobre a colaboração entre as empresas e as universidades em pesquisa e desenvolvimento (P\&D), sendo 1 (não colabora) e 7 (colabora extensivamente).

$\gg$ Aquisição pública de produtos inovadores: índice gerado a partir da Pesquisa de Opinião, em que os gestores registram suas percepçóes sobre até que ponto as decisóes de compra do governo estimulam a inovação, sendo 1 (de forma alguma) e 7 (em grande medida).

$\gg$ Disponibilidade de engenheiros e cientistas: índice gerado a partir da Pesquisa de Opiniáo, em que os gestores registram suas percepçóes sobre até que ponto os cientistas e engenheiros estão disponíveis, sendo 1 (de forma alguma) e 7 (amplamente disponível).

$\gg$ Capacidade para inovar: índice gerado a partir da Pesquisa de Opinião, em que os gestores registram suas percepçóes sobre até que ponto as empresas têm capacidade de inovar, sendo 1 (de forma alguma) e 7 (em grande medida).

Nota: As variáveis $X_{1}$ a $X_{8}$ foram provenientes dos Índices de Liberdade Econômica, divulgados pela Heritage Foundation (2018). Já os dados relativos as variáveis $X_{9}$ a $X_{30}$ são fornecidos pelos relatórios de competitividade global, publicados pelo World Economic Forum (WEF, 2006-2016).

Fonte: Elaboração própria, com base nos dados da Heritage Foundation (2018) e do World Economic Forum (WEF, 2006 a 2016). 


\section{Referências}

Abramovitz, Moses (1986), "Catching up, forging ahead, and falling behind", The Journal of Economic History, 46 (2), New York, Cambridge University Press, pp. 385-406, doi: doi.org/10.1017/ S0022050700046209

Adelman, Irma and Morris, Cynthia Taft (1965), "A Factor Analysis of the Interrelationship Between Social and Political Variables and Per Capita Gross National Product", Quarterly Journal of Economics, 79 (4), Cambridge, Oxford University Press, pp. 555-578, doi: doi.org/10.2307/1880652

Arbix, Glauco (2020), "Ciência e tecnologia em um mundo de pontacabeça", Estudos Avançados, 34 (99), São Paulo, Universidade de Sáo Paulo, pp. 65-76, doi: doi.org/10.1590/s01034014.2020.3499.005

Arellano, Manuel and Bond, Stephen (1991), "Some tests of specification for panel data: Monte Carlo evidence and an application to employment equations", The Review of Economic Studies, 58 (2), Oxford, Oxford University Press, pp. 277-297, doi: doi. org/10.2307/2297968.x

Arellano, Manuel and Bover, Olympia (1995), "Another look at the instrumental variable Estimation of error components models", Journal of Econometrics, 68 (1), New York, Elsevier, pp. 29-51, doi: doi.org/10.1016/0304-4076(94)01642-D

Bonelli, Regis (2009), "Estado e economia: estado e crescimento econômico no Brasil”, Texto para discussão n ${ }^{\circ} 1393$, Brasília, Instituto de Pesquisa Econômica Aplicada.

Bose, Niloy; Haque, Emranul and Osborn, Denise (2007), "Public expenditure and economic growth: a disaggregated analysis for developing countries", The Manchester School, 75 (5), Manchester, Wiley, pp. 533-556, doi: doi.org/10.1111/j.1467-9957. 2007.01028

Blundell, Richard and Bond, Stephen (1998), "Initial conditions and moment restrictions in Dynamic panel data models", Journal of Econometrics, 87 (1), New York, Elsevier, pp. 115-143, doi: doi. org/10.1016/S0304-4076(98)00009-8 
Cameron, Colin and Trivedi, Pravin (2009), Microeconometrics using Stata, College Station, Stata Press.

Choi, Hyungsub (2007), “On Linsu Kim's Imitation to Innovation: The Dynamics of Korea's Technological Learning”, East Asian Science, Technology and Society: an International Journal, 1 (2), Boston, Duke University Press, pp. 259-261, doi: doi.org/10.1007/ s12280-007-9017-2

Cohen, Wesley and Levinthal, Daniel (1990), "Absorptive capacity: a new perspective on learning and innovation", Administrative Science Quarterly, 35 (1), New York, SAGE Journals, pp. 128-152.

Da Cruz Ourives, Ligia Helena (2006), "Estratégias de Crescimento e Padrão de Endividamento: Uma Análise de Painel Dinâmico para Países da América Latina e do Caribe”, Revista Economia, 7 (4), Brasília, Associação Nacional dos Centros de Pós-Graduação em Economia, pp. 71-97.

Edquist, Charles (2009), "Systems of Innovation: Perspectives and Challenges", in Jan Fagerberg and David Mowery (eds.), The Oxford Handbook of Innovation, Oxford, Oxford University Press, doi: doi.org/10.1093/oxfordhb/9780199286805.003.0007

Fagerberg, Jan; Feldman, Maryann and Srholec, Martin (2013), “Technological dynamics and social capability: US states and European nations", Journal of Economic Geography, 14 (2), Oxford, Oxford University Press, pp. 313-337, doi: doi.org/10.1093/jeg/lbt026

Fagerberg, Jan; Lundvall, Bengt-Ake and Srholec, Martin (2017), "Global value chains, national innovation systems and economic development", The European Journal of Development Research, 30 (3), London, Palgrave Macmillan, pp. 533-556, doi.org /10.1057/ s41287-018-0147-2

Fagerberg, Jan and Srholec, Martin (2017), "Capabilities, Economic Development, Sustainability", Cambridge Journal of Economics, 41 (3), Oxford, Oxford University Press, pp. 905-926, doi: doi. org/10.1093/cje/bew061

Fagerberg, Jan and Srholec, Martin (2016), "Global dynamics, capabilities and the crisis", Journal of Evolutionary Economics, 26 (4), 
Basel, Springer, pp. 765-784, doi: doi.org/10.1007/s00191-0160453-9

Fagerberg, Jan and Srholec, Martin (2008), "National innovation systems, capabilities and economic development", Research Policy, 37 (9), Amsterdam, Elsevier, pp. 1417-1435, doi: doi.org /10.1016/j. respol.2008.06.003

Fagerberg, Jan and Srholec, Martin (2005), "Catching up: What are the critical factors for success?" Background paper for the UNIDO Industrial Development Report, Vienna, United Nations Industrial Development Organization, <https://cutt.ly/IjAaJZt>, 29 de novembro de 2020.

Fagerberg, Jan; Srholec, Martin and Knell, Mark (2007), "The competitiveness of nations: why some countries prosper while others fall behind", World Development, 35 (10), New York, Elsevier, pp. 1595-1620, doi: doi.org/10.1016/j.worlddev.2007.01.004

Fávero, Luiz Paulo e Belfiore, Patrícia (2017), Manual de análise de dados: Estatística e modelagem multivariada com Excel, SPSS e Stata, São Paulo, Grupo Editorial Nacional.

Ferraz, João Carlos; Kupfer, David e Haguenauer, Lia (1996), Made in Brazil: desafios competitivos para a indústria, Rio de Janeiro, Campus.

FGV (Fundação Getúlio Vargas) (2017), "Comitê de datação de ciclos econômicos", Rio de Janeiro, FGV, <https://portalibre.fgv.br/ codace>, 15 de janeiro de 2018 .

Freeman, Chris (1995), “The 'National System of Innovation' in historical perspective", Cambridge Journal of Economics, 19 (1), Oxford, Oxford University Press, pp. 5-24, doi: 10.1093/oxfordjournals. cje.a035309

Heritage Foundation (2018), Index of Economic Freedom Explore the Data, Washington D.C., The Heritage Foundation, <https://goo.gl/ oSxjdK>, 10 de janeiro de 2018.

Kaufmann, Daniel; Kraay, Aart e Mastruzzi, Massimo (2009), “Governance Matters VIII Aggregate and Individual Governance Indicators 1996-2008”, Washington D.C., The World Bank. 
Leão, Rafael e Giesteira, Luis Felipe (2020), “Políticas de desenvolvimento produtivo, tecnológico e de inovação: a perspectiva da segurança nacional”, Radar, 62 (1), Brasília, Instituto de Pesquisa Econômica Aplicada, pp. 29-33.

Neduziak, Luiz Carlos Ribeiro e Correia, Fernando Motta (2017), "Alocação dos gastos públicos e crescimento econômico: um estudo em painel para os estados brasileiros", Revista de Administração Pública, 51 (4), Rio de Janeiro, Fundação Getúlio Vargas, pp. 616-632, doi: 10.1590/0034-7612155177

Nelson, Richard (1993), National Innovation Systems - A comparative Analysis, Oxford, Oxford University Press.

OECD-EC-IMF-UN (Organisation for Economic Co-Operation and Development / European Communities / International Monetary Fund / United Nations e World Bank (2009), System of National Accounts 2008, New York, World Bank.

Rocha, Marcos e Oreiro, José Luís (2008), “A experiência internacional de regimes de metas de inflação: uma análise com painel dinâmico", Nova Economia, 18 (2), Belo Horizonte, Universidade Federal de Minas Gerais, pp. 267-291, doi: 10.1590/S010363512008000200004

Rodrigues, Rodrigo Vilela e Teixeira, Erly Cardoso (2010), “Gasto público e crescimento econômico no Brasil: uma análise comparativa dos gastos das esferas de governo", Revista Brasileira de Economia, 64 (4), Rio de Janeiro, Fundação Getúlio Vargas, pp. 423-438, doi: 10.1590/S0034-71402010000400005

Romer, David (2001), Advanced Macroeconomics, New York, McGraw-Hill.

SPSS (2012), Spss: Released 2011. IBM SPSS Statistics for Windows, Version 20.0. Armonk, NY: IBM Corp.

STATA (2015), Stata: Release 14. Statistical Software. College Station, TX: StataCorp LP.

Todaro, Michael Paul and Smith, Stephen Charles (2012), Economic development, Boston, Pearson. 
UN (United Nations Organization) (2017), “Annual Statistical Report on United Nations Procurement 2016”, Copenhagen, UN <https:// cutt.ly/pjAa6YX>, 17 de janeiro de 2018.

WEF (World Economic Forum) (2006), The Global Competitiveness Report 2006-2007, Genebra, World Economic Forum, <https://goo.gl/ wPZSTT>, 10 de janeiro de 2018.

WEF (World Economic Forum) (2007), The Global Competitiveness Report 2007-2008, Genebra, World Economic Forum, <https://goo. $\mathrm{gl} / 2 \mathrm{pFTXu} \geq 10$ de janeiro de 2018.

WEF (World Economic Forum) (2008), The Global Competitiveness Report 2008-2009, Genebra, World Economic Forum, <https://goo.gl/ ctHWfi>, 10 de janeiro de 2018.

WEF (World Economic Forum) (2009), The Global Competitiveness Report 2009-2010, Genebra, World Economic Forum, <https:/goo.gl/ iWa7hxi>, 10 de janeiro de 2018.

WEF (World Economic Forum) (2010), The Global Competitiveness Report 2010-2011, Genebra, World Economic Forum, <https://goo.gl/ ehjW2M>, 10 de janeiro de 2018.

WEF (World Economic Forum) (2011), The Global Competitiveness Report 2011-2012, Genebra, World Economic Forum, < https://goo.gl/ jhv3VL>, 10 de janeiro de 2018.

WEF (World Economic Forum) (2012), The Global Competitiveness Report 2012-2013, Genebra, World Economic Forum, <https://goo.gl/ DK5YDg>, 10 de janeiro de 2018.

WEF (World Economic Forum) (2013), The Global Competitiveness Report 2013-2014, Genebra, World Economic Forum, <https://goo.gl/ LMXFrn>, 10 de janeiro de 2018.

WEF (World Economic Forum) (2014), The Global Competitiveness Report 2014-2015, Genebra, World Economic Forum, <https://goo.gl/ YKJSN9>, 10 de janeiro de 2018.

WEF (World Economic Forum) (2015), The Global Competitiveness Report 2015-2016, Genebra, World Economic Forum, <https://goo.gl/ sdpCR9>, 10 de janeiro de 2018. 
WEF (World Economic Forum) (2016), The Global Competitiveness Report 2016-2017, Genebra, World Economic Forum, <https://goo.gl/ Dftei6>, 10 de janeiro de 2018.

WEF (World Economic Forum) (2018), The Global Competitiveness Report 2018, Genebra, World Economic Forum, <https://bit.ly/3dKccQX>, 09 de outubro de 2020.

Recebido: 27 de março de 2020. Encaminhado: 29 de setembro de 2020. Aceito: 5 de novembro de 2020.

Raniella Orquiza da Silva. Mestra em Economia pela Universidade Federal de Viçosa. As linhas de investigação referem-se a políticas públicas e mercado de trabalho. Entre suas mais recentes publicaçóes destacam-se como coautora em: "Efeito da utilização de assistência técnica sobre a renda de produtores familiares do Brasil no ano de 2014", Revista de Economia e Sociologia Rural, 58 (2), Brasília, Sociedade Brasileira de Economia e Sociologia Rural, pp. 1-16 (2020); como autora "Trabalho infantil e pobreza: uma análise no contexto de recessão econômica brasileira”, Revista de Desenvolvimento Econômico, 2 (40), Salvador, Universidade Salvador, pp. 463-488 (2018); como coautora em "Análise por gênero da produção do corpo docente dos cursos de Economia nas Universidades Federais de Minas Gerais", Oikos: Família e Sociedade em Debate, 29 (1), Viçosa, Universidade Federal de Viçosa, pp. 102-124 (2018).

Waldemiro Peterle Neto. Bacharel em Ciências Econômicas pela Universidade Federal de Viçosa (UFV). Atualmente é Analista de Inteligência de Mercado na Indústria de Cosméticos Haskell. Entre suas mais recentes publicações destacam-se, em coautoria: "Efeito da utilização de assistência técnica sobre a renda de produtores familiares do Brasil no ano de 2014", Revista de Economia e Sociologia Rural, 58 (2), Brasília, Sociedade Brasileira de Economia e Sociologia Rural, pp. 1-16 (2020); "Uma análise de eficiência para os senadores brasileiros", Revista de Desenvolvimento e Políticas Públicas, 2 (1), Viçosa, Universidade Federal de Viçosa, pp. 3-20 (2018), e "Trabalho infantil e pobreza: uma análise no contexto de recessão econômica brasileira", Revista de Desenvolvimento Econômico, 2 (40), Salvador, Universidade Salvador, pp. 463-488 (2018).

Evandro Camargos Teixeira. Doutor em Economia Aplicada pela Escola Superior de Agricultura Luiz de Queiroz - Universidade de São Paulo (ESALQ/USP). Atualmente é Professor Associado I do Departamento de 
Economia da Universidade Federal de Viçosa (UFV). As linhas de investigação referem-se à área de desenvolvimento econômico, economia da criminalidade e economia da saúde. Entre suas mais recentes publicaçóes destacam-se, em coautoria: "Pandemia da COVID-19 e ocupação no mercado de trabalho: o caso da região nordeste do Brasil", EconômicaNiterói, 22 (1), Niterói, Universidade Federal Fluminense, pp 9-30 (2020); "Efeitos dos investimentos em infraestrutura pública sobre a pobreza e pobreza extrema na América Latina”, Economía, Sociedad y Territorio, 20 (64), Zinacantepec, El Colegio Mexiquense, A.C., pp. 667-692, (2020), e "Mensuração da Pobreza Multidimensional Rural nas Mesorregióes Norte e Jequitinhonha de Minas Gerais", Revista de Economia e Sociologia Rural, 57 (1), Brasília, Sociedade Brasileira de Economia e Sociologia Rural, pp. 161-180 (2019). 